\title{
Pengaruh Media Tanam Hidroponik terhadap Pertumbuhan Bayam (Amaranthus sp.) dan Selada (Lactuca sativa)
}

\section{The Effect of Hydroponic Growing Media on Spinach (Amaranthus sp.) and Lettuce (Lactuca sativa) Growth}

\author{
Renna Eliana Warjoto*, Joshua Mulyawan, dan Tati Barus
}

Program Studi Bioteknologi, Fakultas Teknobiologi, Universitas Katolik Indonesia Atma Jaya *E-mail: renna.eliana@atmajaya.ac.id; rennaeliana@gmail.com

\begin{abstract}
As the human population rises, the demand for high nutritional foods, such as vegetables, also increases. However, agricultural land, especially in urban areas, is narrowing. Hydroponics can be one of the solutions to answer this problem. In addition to complete nutrition, hydroponic plants also require appropriate media for root attachment, water absorption, and aeration. Unfortunately, no studies have compared the growth of hydroponic plants using rockwool and sponge as affordable growing media. Therefore, this study aimed to determine the effect of local rockwool, imported rockwool, and sponge as growing media on the growth of spinach (Amaranthus sp.) and lettuce (Lactuca sativa) using Deep Flow Technique (DFT). This study used a Completely Randomized Design with three treatment groups, i.e., three different growing media, for spinach and lettuce. At the harvest period, the number of leaves on each plant was counted, the crown fresh-weight was balanced, and the chlorophyll content was determined. Plant height was also measured for spinach. The results showed that the three types of growing media had no significant effect on the number of leaves, plant height, crown fresh-weight, and chlorophyll content of spinach. However, the number of leaves $(25.25 \pm 1.38)$ and the crown fresh-weight $(141.27 \pm 16.49 \mathrm{~g})$ of lettuce grown on the local rockwool media were significantly higher than the number of leaves $(17.00 \pm 0.77)$ and the crown fresh-weight $(81.48 \pm 9.50 \mathrm{~g})$ of lettuce planted on the sponge media. Other hydroponic growing media's influences can be investigated for further research, with additional growth parameters such as crown dry-weight, root fresh-and dryweight, as well as the determination of plant phytochemical contents. Moreover, the correlation between nutritional formulations and the type of growing media can be further examined to obtain the most optimum spinach and lettuce growth.
\end{abstract}

Keywords: Hydroponics, lettuce, rockwool, spinach, sponge

Disubmit : 21 Mei 2020; Diterima: 25 Juni 2020; Disetujui : 25 Agustus 2020

\section{PENDAHULUAN}

Seiring dengan bertambahnya jumlah penduduk, kebutuhan masyarakat terhadap bahan pangan bernutrisi tinggi, seperti sayuran, semakin meningkat (LeMonte et al., 2016) namun lahan pertanian yang tersedia, khususnya di perkotaan semakin terbatas. Sistem pertanian hidroponik menjadi salah satu alternatif yang dapat menjawab permasalahan tersebut. Pertanian hidroponik memiliki berbagai keunggulan, seperti kebutuhan lahan yang relatif sempit (Siswanto \& Widoretno, 2017), rendahnya tingkat serangan hama dan penyakit karena kondisi lingkungan yang terkendali (Abdullah, 2016), meningkatnya pertumbuhan dan 
produksi (yield) tanaman karena pemberian nutrisi yang lebih terkontrol (Barbosa et al., 2015; Abdullah, 2016), hematnya penggunaan pupuk dan air (Putra \& Yuliando, 2015; Alshrouf, 2017), serta terhindarnya tanaman dari kekeringan, erosi, dan banjir (Barbosa et al., 2015). Sayuran yang ditumbuhkan dengan metode hidroponik juga pada umumnya lebih bersih dan mempunyai cita rasa yang lebih enak daripada sayuran yang ditanam secara konvensional (Putra \& Yuliando, 2015).

Salah satu sistem hidroponik yang relatif mudah dan umum digunakan adalah Deep Flow Technique (DFT). Sistem ini dapat menampung air dengan kedalaman $5 \mathrm{~cm}$ atau lebih (Vermeulen \& Kamstra, 2013), sehingga dapat mempertahankan sirkulasi dan ketersediaan air meskipun terjadi masalah pada pelistrikan yang menyebabkan disfungsi pompa. Dengan demikian, akar tanaman tetap dapat memperoleh suplai air dan nutrisi (Moesa, 2016). Vimolmangkang et al. (2010) melaporkan keefektifan DFT untuk panen dan produksi minyak atsiri dari spearmint (Mentha spicata L.) dan Japanese mint (M. arvensis L. var. piperascens Malinv.). Hal-hal inilah yang mendasari pemilihan DFT untuk sistem hidroponik yang digunakan dalam penelitian ini.

Agar dapat tumbuh dengan baik, tanaman yang dibudidayakan secara hidroponik perlu mendapatkan nutrisi lengkap, yakni yang terdiri dari unsur-unsur makro (N, P, K, Ca, $\mathrm{Mg}, \mathrm{S})$ dan mikro $(\mathrm{Cl}, \mathrm{Mn}, \mathrm{Fe}, \mathrm{Cu}$, Zn, B, dan Mo) (Chekli et al., 2017). Selain itu, jenis media tanam juga berpengaruh pada tingkat produksi (yield) tanaman, kandungan biomassa kering (dry matter), serta kualitas tanaman yang mencakup tekstur, warna, dan rasa (Putra \& Yuliando, 2015). Media tanam berfungsi sebagai tempat melekatnya akar, penyokong bagi tanaman, dan perantara larutan nutrisi (Ainina \& Aini, 2018). Jenis media tanam yang umum digunakan dalam pertanian hidroponik adalah rockwool. Media tanam rockwool terbuat dari gabungan batu bara, batu kapur, dan batu basalt yang diproses dengan suhu tinggi hingga membentuk serat-serat. Proses pembuatan rockwool yang melibatkan suhu tinggi membuatnya steril dari mikroorganisme patogen, hama, ataupun benih gulma. Air juga mudah terlepas dari serat-serat rockwool sehingga struktur rockwool memberikan rasio air dan udara yang optimum bagi pertumbuhan tanaman (Bussell \& McKennie, 2004). Rockwool bersifat inert secara biologis dan kimiawi sehingga penggunaannya tidak akan memodifikasi atau membatasi suplai nutrisi bagi tanaman. Lebih dari 98\% air dan unsur-unsur hara dapat diserap oleh tanaman dalam sistem hidroponik dengan rockwool sebagai media tanam (Bussell \& McKennie, 2004). Meskipun demikian, penggunaan rockwool dianggap belum berkelanjutan, dan seratnya pernah diduga memicu kanker paru-paru (Drent et al., 2000; Bussell \& McKennie, 2004). World Health Organization (WHO) kemudian mengevaluasi kembali risiko karsinogenik serat- serat vitreous seperti yang ada pada rockwool, dan akhirnya mengklasifikasikan rockwool sebagai materi yang non-karsinogenik bagi manusia (IARC, 2001).

Meskipun rockwool sudah umum digunakan sebagai media tanam hidroponik, eksplorasi bahan media tanam lain yang mudah diperoleh dan terjangkau masih menarik untuk diteliti. Salah satunya adalah bahan spons. Spons mudah diperoleh, terjangkau, dan diketahui oleh semua kalangan masyarakat, termasuk yang masih awam terhadap sistem pertanian hidroponik. Terdapat berbagai jenis spons berdasarkan bahan pembuatannya, salah satunya adalah spons yang berbahan polyurethane. Spons jenis ini bersifat sintetis, umum digunakan dalam keperluan sehari-hari, serta memiliki sifat mekanis dan elastisitas yang baik (Permono, 2018). Menurut sepengetahuan penulis, hingga saat ini masih belum ada penelitian yang membandingkan pertumbuhan tanaman yang dibudidayakan secara hidroponik menggunakan media tanam rockwool dan spons. Oleh sebab itu, pengaruh media tanam rockwool lokal, rockwool impor, dan spons terhadap pertumbuhan bayam (Amaranthus sp.) dan selada (Lactuca sativa) pada hidroponik DFT akan ditentukan dalam penelitian ini. Kedua sayuran ini dipilih karena umum ditemukan di masyarakat serta memiliki kandungan gizi seperti phylloquinone atau Vitamin K1 (de Borst et al., 2016) dan senyawa fitokimia (Randhawa et al., 2015) yang tinggi. 


\section{METODE PENELITIAN}

Penelitian ini dirancang menggunakan Rancangan Acak Lengkap (RAL) dengan tiga perlakuan (tiga media tanam berbeda) untuk setiap jenis tanaman. Pada setiap perlakuan dilakukan enam kali pengulangan. Benih bayam (Amaranthus sp.) dan selada (L. sativa) (PT. Known You Seed Indonesia) disemai pada tiga jenis media tanam, yakni rockwool lokal, rockwool impor, dan spons (Scotch Brite). Media rockwool lokal dan rockwool impor dibeli dari praktisi hidroponik di daerah Tangerang Selatan. Nutrisi hidroponik yang digunakan dalam penelitian ini adalah $\mathrm{AB}$ Mix Hidro J. Penelitian ini dilakukan di rumah kaca dan laboratorium Kultur Jaringan Tanaman Fakultas Teknobiologi Universitas Katolik Indonesia Atma Jaya.

Tahap penyemaian benih. Masing-masing media tanam dipotong dengan ukuran $2,5 \mathrm{~cm} \times 2,5 \mathrm{~cm} \times$ 2,5 cm dan direndam dalam air hingga basah. Satu butir benih selada dan dua butir benih bayam diletakkan pada masing-masing media tanam yang sudah dilubangi menggunakan tusuk gigi. Kelembapan media tanam dijaga agar proses perkecambahan dapat berlangsung dengan baik.

Pindah tanam dan pemberian nutrisi. Setiap tanaman dipindahkan ke perangkat hidroponik pada usia 10 hari setelah semai, yakni saat tanaman secara umum sudah berdaun empat. Tanaman ditempatkan pada net pot di perangkat hidroponik DFT. Pemberian nutrisi dilakukan dengan cara melarutkan nutrisi AB Mix dalam air menurut konsentrasi yang tertera pada Tabel 1.

Tabel 1. Pengaturan konsentrasi nutrisi AB Mix

\begin{tabular}{cccc}
\hline \multirow{2}{*}{ Jenis tanaman } & \multicolumn{3}{c}{ Konsentrasi nutrisi (ppm) } \\
\cline { 2 - 4 } & $\mathrm{H} 10$ & $\mathrm{H} 17$ & H24 hingga panen \\
\hline Bayam & 600 & 1.000 & 1.500 \\
Selada & 600 & 1.000 & 1.200 \\
\hline
\end{tabular}

H10: hari ke-10 setelah semai; H17: hari ke-17 setelah semai; H24: hari ke-24 setelah semai

Pemanenan dan pengukuran pertumbuhan tanaman. Bayam dipanen pada hari ke-39 dan selada dipanen pada hari ke-56 setelah semai. Parameter yang diamati dan diukur ketika panen yaitu jumlah daun, bobot segar tajuk, dan kadar klorofil. Pengukuran tinggi tanaman khusus dilakukan pada bayam.

Penentuan kadar klorofil. Klorofil diekstrak dari daun tanaman, dan kadarnya ditentukan menurut metode Harbourne (1973). Sebanyak 0,1 g daun ditimbang, lalu ditambahkan $10 \mathrm{~mL}$ aseton $80 \%$. Penggerusan dalam mortar selanjutnya dilakukan untuk mengekstrak klorofil. Kemudian hasil penggerusan disentrifugasi dengan kecepatan $3.000 \mathrm{rpm}$ selama 15 menit dan larutan disaring menggunakan kertas filter Whatman 41. Larutan selanjutnya dimasukkan ke dalam kuvet dan kadar klorofil diukur menggunakan spektrofotometer pada panjang gelombang 646 dan $663 \mathrm{~nm}$. Kadar klorofil ditentukan dengan rumus di bawah ini.

Kadar klorofil a $=12,21$ (A.663) $-2,81$ (A.646) $\mathrm{mg} / \mathrm{L}$.

Kadar klorofil $b=20,13$ (A.646) - 5,03 (A.663) mg/L.

Kadar klorofil total $=7,18$ (A.663) $+17,3$ (A.646) $\mathrm{mg} / \mathrm{L}$.

Analisis statistik. Data dikelompokkan berdasarkan kombinasi jenis tanaman dan media tanam, kemudian dilakukan uji normalitas dan homogenitas variansi. Normalitas data dianalisis menggunakan uji Saphiro-Wilk dan homogenitas variansi data dievaluasi menggunakan uji Levene. Apabila data terdistribusi normal dan variansinya homogen, maka dilakukan analisis parametrik Analysis of Variance (ANOVA) dan uji post-hoc Least Significant Difference (LSD). Namun, jika data tidak terdistribusi normal dan/atau variansinya tidak homogen, maka dilakukan analisis nonparametrik Kruskal-Wallis dengan uji post-hoc Stepwise step-down multiple comparison. Semua analisis dilakukan dalam selang kepercayaan 95\% (taraf signifikansi 5\%). 
Warjoto, R.E., dkk: Pengaruh Media Tanam Hidroponik terhadap Pertumbuhan Bayam (Amaranthus sp .......

\section{HASIL DAN PEMBAHASAN}

Setelah dilakukan uji normalitas dan homogenitas variansi data, diketahui bahwa tidak semua data mempunyai persebaran normal dan tidak semua data menunjukkan variansi homogen. Oleh sebab itu, data selanjutnya dianalisis secara nonparametrik menggunakan metode Kruskal-Wallis dengan uji post-hoc Stepwise step-down multiple comparison (taraf signifikansi 5\%).

Hasil penelitian menunjukkan bahwa jumlah daun bayam yang ditanam pada media rockwool impor (16,86 $\pm 1,60$ helai) lebih banyak daripada jumlah daun bayam yang ditanam pada rockwool lokal (14,50 \pm 1,84 helai) dan spons (12,50 $\pm 0,92$ helai), namun tidak berbeda secara signifikan (Tabel 2). Media rockwool lokal memberikan hasil terbaik pada parameter pertumbuhan tinggi bayam $(26,42 \pm 1,42 \mathrm{~cm})$ dan bobot segar tajuk bayam $(19,23 \pm 3,38 \mathrm{~cm})$, meskipun tidak berbeda secara signifikan (Gambar 1, Tabel 2).

Jumlah daun selada yang ditanam pada media rockwool lokal $(25,25 \pm 1,38$ helai) paling banyak dan berbeda secara signifikan jika dibandingkan dengan jumlah daun selada yang ditanam pada media spons (17,00 $\pm 0,77$ helai), meskipun tidak berbeda secara signifikan dari jumlah daun selada pada media rockwool impor (20,67 $\pm 1,73$ helai). Parameter tinggi tanaman tidak diterapkan pada selada karena struktur batang selada yang pendek dengan helai daun yang lebar (Gambar 2). Bobot segar tajuk selada yang ditanam pada media rockwool lokal $(141,27 \pm 16,49 \mathrm{~g})$ juga ditemukan paling tinggi dan berbeda secara signifikan dari bobot segar tajuk selada pada media spons $(81,48 \pm 9,50 \mathrm{~g})$, namun tidak berbeda signifikan dengan bobot segar tajuk selada pada media rockwool impor $(121,98 \pm 13,38 \mathrm{~g})$.

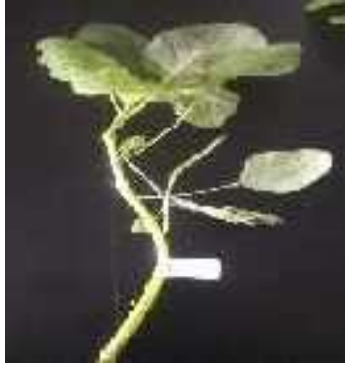

a

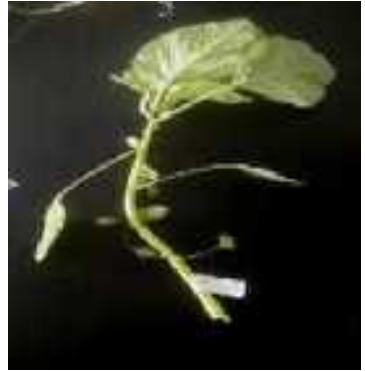

b

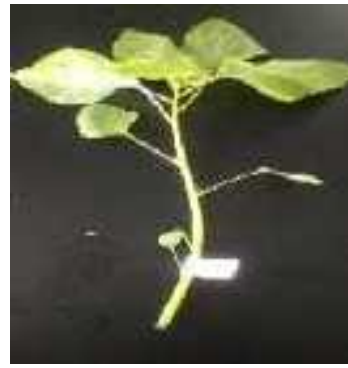

$\mathrm{c}$

Gambar 1. Penampakan visual bayam (Amaranthus sp.) yang ditanam pada media rockwool lokal (a), rockwool impor (b), dan spons (c) saat panen (hari ke-39 setelah semai)

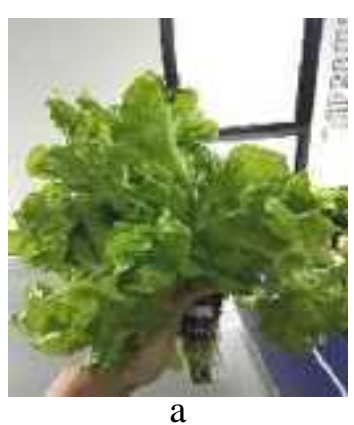

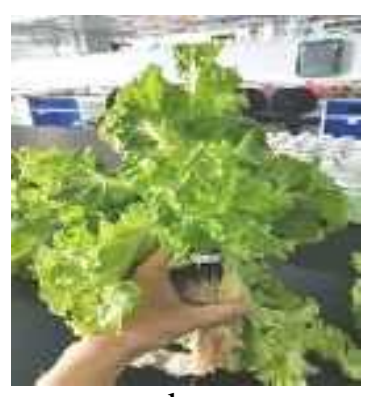

$\mathrm{b}$

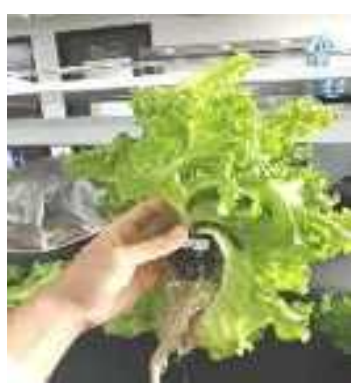

$\mathrm{c}$

Gambar 2. Penampakan visual selada (Lactuca sativa) yang ditanam pada media rockwool lokal (a), rockwool impor (b), dan spons (c) saat panen (hari ke-56 setelah semai) 
Tabel 2. Pengaruh media tanam terhadap pertumbuhan bayam (Amaranthus sp.) dan selada (Lactuca sativa) dengan media tanam berbeda

\begin{tabular}{ccccc}
\hline \multirow{2}{*}{ No. } & Kombinasi tanaman dan & \multicolumn{3}{c}{ Parameter pertumbuhan *) } \\
\cline { 3 - 5 } & media tanam & Jumlah daun (helai) & Tinggi tanaman $(\mathrm{cm})$ & Bobot segar tajuk $(\mathrm{g})$ \\
\hline 1 & Bayam - Rockwool Lokal & $14,50 \pm 1,84^{\mathrm{ab}}$ & $26,42 \pm 1,42^{\mathrm{a}}$ & $19,23 \pm 3,38^{\mathrm{a}}$ \\
2 & Bayam - Rockwool Impor & $16,86 \pm 1,60^{\mathrm{ab}}$ & $23,14 \pm 1,44^{\mathrm{a}}$ & $15,79 \pm 2,72^{\mathrm{a}}$ \\
3 & Bayam - Spons & $12,50 \pm 0,92^{\mathrm{a}}$ & $23,85 \pm 1,16^{\mathrm{a}}$ & $11,45 \pm 0,69^{\mathrm{a}}$ \\
4 & Selada - Rockwool Lokal & $25,25 \pm 1,38^{\mathrm{c}}$ & ND & $141,27 \pm 16,49^{\mathrm{c}}$ \\
5 & Selada - Rockwool Impor & $20,67 \pm 1,73^{\mathrm{bc}}$ & ND & $121,98 \pm 13,38^{\mathrm{bc}}$ \\
6 & Selada - Spons & $17,00 \pm 0,77^{\mathrm{ab}}$ & ND & $81,48 \pm 9,50^{\mathrm{b}}$ \\
\hline
\end{tabular}

*) Data ditampilkan sebagai rataan \pm SE. Huruf ${ }^{\text {abc }}$ menunjukkan signifikansi pada setiap parameter pertumbuhan $(p \leq 0.05)$. ND: not determined.

Penelitian ini, densitas rockwool lokal $(60 \mathrm{~kg} / \mathrm{m} 3)$ diketahui lebih besar daripada rockwool impor (45 $\mathrm{kg} / \mathrm{m} 3$ ). Rockwool lokal juga mempunyai orientasi serat horizontal dengan densitas berlapis. Kapasitas rockwool untuk menahan air (water holding capacity) dan kemampuannya untuk menyediakan aerasi dipengaruhi oleh densitas dan orientasi serat-seratnya. Rockwool dengan serat berdensitas rendah cenderung mempunyai waktu pakai yang lebih pendek (short life) jika dibandingkan dengan rockwool berdensitas tinggi. Perbedaan densitas ini juga diduga berpengaruh terhadap kemampuan kedua jenis rockwool menahan air. Rockwool dengan orientasi serat horizontal dan densitas berlapis mempunyai water holding capacity dan kemampuan aerasi yang lebih baik daripada rockwool dengan orientasi serat vertikal untuk aplikasi pertanian hidroponik (Bussell \& McKennie, 2004).

Di sisi lain, densitas spons lebih rendah daripada rockwool lokal maupun impor, dan secara kualitatif pori-pori spons juga lebih besar daripada rockwool. Hal ini diduga menyebabkan rendahnya water holding capacity spons, sehingga ketersediaan air dalam media spons yang dapat diserap oleh akar tanaman juga lebih rendah daripada ketersediaannya dalam media rockwool. Meskipun demikian, hal ini baru nampak secara signifikan pada jumlah daun dan bobot segar tajuk selada. Jumlah daun dan bobot segar tajuk selada yang ditanam pada media spons lebih rendah secara signifikan daripada jumlah daun dan bobot segar tajuk selada yang ditanam pada media rockwool lokal (Tabel 2). Bobot segar tajuk tanaman mengindikasikan bobot komponen organik penyusun tajuk tanaman ditambah kadar air dalam jaringan tanaman. Kadar air dalam 100 g selada (95.64\%) (USDA, 2020a) diketahui lebih tinggi daripada kadar air dalam $100 \mathrm{~g}$ bayam (91.4\%) (USDA, 2020b).

Hlophe et al. (2019) melaporkan bahwa tanaman Swiss chard (Beta vulgaris var. cicla) yang ditumbuhkan secara hidroponik pada media tanam berporositas tinggi mempunyai jumlah daun dan bobot segar yang cenderung rendah. Hal ini disebabkan oleh rendahnya kemampuan media berporositas tinggi untuk menahan nutrisi dan air (Hlophe et al., 2019) Apabila ketersediaan air dalam media tanam mencukupi, maka kandungan air dalam jaringan tanaman dapat semakin tinggi (Bozkurt et al., 2009; Nugraheni et al., 2018). Tanaman membutuhkan air sebagai kompensasi adanya peristiwa evapotranspirasi (Bozkurt et al., 2009) dan sebagai media penunjang berbagai reaksi biokimiawi dalam sel termasuk fotosintesis (Nugraheni et al., 2018). Proses absorpsi air dan fotosintesis yang berjalan baik akan menstimulasi akumulasi karbohidrat dan protein pada tajuk tanaman, sehingga berkontribusi pada bobot segar tajuk tanaman (Nugraheni et al., 2018) Hal ini nampak lebih jelas pada selada karena luas penampang daun selada lebih besar daripada bayam (Gambar 1 dan 2), sehingga selada diduga membutuhkan lebih banyak air untuk mengimbangi laju evapotranspirasi di daun.

Kadar klorofil a $(7,10 \pm 0,21 \mathrm{mg} / \mathrm{L}), \mathrm{b}(7,36 \pm 0.28 \mathrm{mg} / \mathrm{L})$, dan klorofil total $(14,45 \pm 0,48 \mathrm{mg} / \mathrm{L})$ bayam yang ditanam pada media spons sedikit lebih tinggi daripada bayam yang ditanam pada media 
Warjoto, R.E., dkk: Pengaruh Media Tanam Hidroponik terhadap Pertumbuhan Bayam (Amaranthus sp ......

lainnya, namun tidak berbeda secara signifikan (Tabel 3). Selada yang ditanam pada media spons juga mempunyai kadar klorofil a $(6,01 \pm 0,87 \mathrm{mg} / \mathrm{L}), \mathrm{b}(1,80 \pm 0.33 \mathrm{mg} / \mathrm{L})$, dan klorofil total $(7,81 \pm 1,19 \mathrm{mg} / \mathrm{L})$ yang cenderung lebih tinggi daripada media lainnya, meskipun tidak berbeda secara signifikan (Tabel 3).

Tabel 3. Pengaruh media tanam terhadap kadar klorofil bayam (Amaranthus sp.) dan selada (Lactuca sativa) dengan media tanam berbeda

\begin{tabular}{ccccc}
\hline \multirow{2}{*}{ No. } & Kombinasi tanaman dan & \multicolumn{3}{c}{ Kadar klorofil $(\mathrm{mg} / \mathrm{L}) *)$} \\
\cline { 3 - 5 } & media tanam & Klorofil a & Klorofil b & Klorofil total \\
\hline 1 & Bayam - Rockwool Lokal & $6,78 \pm 0,25^{\mathrm{a}}$ & $7,05 \pm 0.35^{\mathrm{b}}$ & $13,82 \pm 0,58^{\mathrm{b}}$ \\
2 & Bayam - Rockwool Impor & $6,87 \pm 0,21^{\mathrm{a}}$ & $7,03 \pm 0.20^{\mathrm{b}}$ & $13,89 \pm 0,37^{\mathrm{b}}$ \\
3 & Bayam - Spons & $7,10 \pm 0,21^{\mathrm{a}}$ & $7,36 \pm 0.28^{\mathrm{b}}$ & $14,45 \pm 0,48^{\mathrm{b}}$ \\
4 & Selada - Rockwool Lokal & $5,75 \pm 0,45^{\mathrm{a}}$ & $1,72 \pm 0.16^{\mathrm{a}}$ & $7,46 \pm 0,60^{\mathrm{a}}$ \\
5 & Selada - Rockwool Impor & $5,03 \pm 1,00^{\mathrm{a}}$ & $1,45 \pm 0.30^{\mathrm{a}}$ & $6,47 \pm 1,29^{\mathrm{a}}$ \\
6 & Selada - Spons & $6,01 \pm 0,87^{\mathrm{a}}$ & $1,80 \pm 0.33^{\mathrm{a}}$ & $7,81 \pm 1,19^{\mathrm{a}}$ \\
\hline
\end{tabular}

*) Data ditampilkan sebagai rataan \pm SE. Huruf ${ }^{a b c}$ menunjukkan signifikansi pada setiap parameter kadar klorofil $(p \leq 0.05)$.

Tidak adanya perbedaan signifikan pada kadar klorofil bayam maupun selada yang ditanam dengan media rockwool lokal, impor, maupun spons menunjukkan bahwa proses sintesis klorofil pada kedua tanaman tidak dipengaruhi oleh ketiga jenis media tanam. Kowalczyk et al., (2016) juga menunjukkan bahwa kadar klorofil selada yang ditanam secara hidroponik menggunakan media rockwool dan sabut kelapa tidak berbeda signifikan. Dalam penelitian ini, tidak ada perbedaan komposisi nutrisi AB Mix yang digunakan selama kultivasi bayam maupun selada pada ketiga jenis media tanam. Kadar klorofil dapat berbeda secara signifikan apabila komposisi nutrisi hidroponik dijadikan sebagai parameter atau peubah bebas, terutama unsur N (nitrogen) (Warganegara et al., 2015; Wen et al., 2019), S (sulfur) (Skudra \& Ruza, 2017), Fe (besi), Zn (seng), dan Mn (mangan) (Roosta et al., 2018).

\section{KESIMPULAN DAN SARAN}

Media tanam rockwool lokal, rockwool impor, dan spons tidak memberikan pengaruh signifikan terhadap pertumbuhan bayam yang mencakup jumlah daun, tinggi tanaman, dan bobot segar tajuk. Namun, jumlah daun dan bobot segar tajuk selada yang ditanam pada media rockwool lokal lebih tinggi secara signifikan daripada jumlah daun dan bobot segar tajuk selada yang ditanam pada media spons. Kadar klorofil $\mathrm{a}, \mathrm{b}$, dan klorofil total bayam maupun selada yang ditumbuhkan pada ketiga jenis media tanam tidak berbeda secara signifikan.

Untuk penelitian lebih lanjut, pengaruh media tanam terhadap bobot kering tajuk, bobot segar dan kering akar, kadar karotenoid, kandungan fenolik total, serta aktivitas antioksidan ekstrak tanaman dapat dievaluasi. Pengaruh jenis media tanam lainnya seperti arang sekam, hidroton, cocopeat, perlit, vermikulit, hydrogel, atau kombinasinya juga menarik untuk diteliti. Selain itu, hubungan antara komposisi nutrisi dan jenis media tanam hidroponik dapat diinvestigasi lebih jauh untuk memperoleh pertumbuhan bayam dan selada yang paling optimum.

\section{UCAPAN TERIMA KASIH}

Penulis mengucapkan terima kasih kepada Lembaga Penelitian dan Pengabdian Masyarakat (LPPM) Universitas Katolik Indonesia Atma Jaya yang telah menyediakan dana penelitian, serta Omah Daun dan para teknisi Fakultas Teknobiologi untuk setiap bantuan yang diberikan selama penelitian ini berlangsung. Penulis juga mengucapkan terima kasih kepada Dr. Rory Hutagalung, D.E.A. yang telah memberikan arahan dalam penentuan metode analisis statistik untuk pengolahan data penelitian ini.

Hal 123 Volume 20 Nomor 2 Tahun 2020 


\section{DAFTAR PUSTAKA}

Abdullah, N. (2016). 'Vertical-horizontal regulated soilless farming via advanced hydroponics for domestic food production in Doha, Qatar', Research Ideas and Outcomes, 2, pp.e8134. doi: 10.3897/rio.2.e8134.

Ainina, A. N. \& Aini, N. (2018) 'Konsentrasi nutrisi AB Mix dan media tanam terhadap pertumbuhan dan hasil tanaman selada merah (Lactuca sativa L. var. crispa) dengan sistem hidroponik substrat', Jurnal Produksi Tanaman, 6(8), pp.1684-1693.

Alshrouf, A. (2017) 'Hydroponics, aeroponic and aquaponic as compared with conventional farming', American Scientific Research Journal for Engineering, 27(1), pp.247-255.

Barbosa, G., Gadelha, F., Kublik, N., Proctor, A., Reichelm, L., Weissinger, E., Wohlleb, G., \& Halden, R. (2015) 'Comparison of land, water, and energy requirements of lettuce grown using hydroponic vs. conventional agricultural methods', International Journal of Environmental Research and Public Health, 12(6), pp.6879-6891. doi: 10.3390/ijerph120606879.

de Borst, M. H., Hill, T. R., \& Morrissey, P. A. (2016) 'Vitamins: Vitamin K'. In: Fuquay, J. W. (ed). Encyclopedia of Dairy Sciences, USA: Elsevier, pp. 661-666.

Bozkurt, S., Mansuroglu, G. S., Kara, M., \& Önder, S. (2009) 'Responses of lettuce to irrigation levels and nitrogen forms', African Journal of Agricultural Research, 4(11), pp.1171-1177.

Bussell, W. T. \& McKennie, S. (2004) 'Rockwool in horticulture, and its importance and sustainable use in New Zealand', New Zealand Journal of Crop and Horticultural Science, 32, pp.29-37. doi: 10.1080/01140671.2004.9514277.

Chekli, L., Kim, J. E., Saliby, I. E., Kim, Y., Phuntsho, S., Li, S., Ghaffour, N., Leiknes, T., \& Shon, H. K. (2017) 'Fertilizer drawn forward osmosis process for sustainable water reuse to grow hydroponic lettuce using commercial nutrient solution', Separation and Purification Technology. doi: 10.1016/j.seppur.2017.03.008.

Drent, M., Bomans, P. H. H., Suylen, R. J. van, Lamers, R. J. S., Bast, A., \& Wouters, E. F. M. (2000). 'Association of man-made mineral fibre exposure and sarcoid-like granulomas', Respiratory Medicine, 94, pp.815-820. doi: 10.1053/rmed.2000.0827.

Harbourne, J. B. (1973). Phytochemical methods: a guide to modern techniques of plant analysis. New York, USA: Chapman and Hall.

Hlophe, P.A., Nxumalo, K. A., Oseni, T. O., Masarirambi, M. T., Wahome, P. K., \& Shongwe, V. D. (2019) 'Effects of different media on the growth and yield of Swiss chard (Beta vulgaris var. cicla) grown in hydroponics', Horticulture International Journal, 3(3), pp. 147-151.

IARC [International Agency for Research on Cancer]. (2001) 'IARC monographs on the evaluation of carcinogenic risks to humans: man-made vitreous fibres'. Lyon, France: World Health Organization.

Kowalczyk, K., Mirgos, M., Bączek, K., Niedzińska, M., \& Gajewski, M. (2016) 'Effect of different growing media in hydroponic culture on the yield and biological quality of lettuce (Lactuca sativa var. capitata)', Acta Horticulturae, pp.105-110. doi: 10.17660/ActaHortic.2016.1142.17.

LeMonte, J. J., Jolley, V. D., Summerhays, J. S., Terry, R. E., \& Hopkins, B. G. (2016) 'Polymer coated urea in turfgrass maintains vigor and mitigates nitrogen's environmental impacts', PLoS ONE, 11(1), pp.e0146761. doi: 10.1371/journal.pone.0146761. 
Warjoto, R.E., dkk: Pengaruh Media Tanam Hidroponik terhadap Pertumbuhan Bayam (Amaranthus sp .......

Moesa, Z. (2016) Hidroponik kreatif, membangun instalasi unik menggunakan barang bekas. Jakarta, Indonesia: AgroMedia Pustaka.

Nugraheni, F. T., Haryanti, S., \& Prihastanti, E. (2018) 'Pengaruh perbedaan kedalaman tanam dan volume air terhadap perkecambahan dan pertumbuhan benih sorgum (Sorghum bicolor (L.) Moench)', Buletin Anatomi dan Fisiologi, 3(2), pp.223-232.

Permono, R. A. (2018) Mengenal polimer dan polimerasisasi. Yogyakarta, Indonesia: Gadjah Mada University Press.

Putra, P. A. \& Yuliando, H. (2015) 'Soilless culture system to support water use efficiency and product quality: a review', Agriculture and Agricultural Science Procedia, 3, pp.283-288. doi: 10.1016/j.aaspro.2015.01.054.

Randhawa, M. A., Atif, M. Khan, A. A., Javed, M. S., \& Sajidm M. W. (2015) 'Green leafy vegetables: a health promoting source'. In: Watson, R. R. (ed). Handbook of Fertility, USA: Elsevier, pp.205220.

Roosta, H. R., Estaji, A. \& Niknam, F. (2018) 'Effect of iron, zinc and manganese shortage-induced change on photosynthetic pigments, some osmoregulators and chlorophyll fluorescence parameters in lettuce', Photosynthetica, 56, pp.606-615. doi: 10.1007/s11099-017-0696-1.

Siswanto, D. \& Widoretno, W. (2017) 'Design and construction of a vertical hydroponic system with semicontinuous and continuous nutrient cycling.', in 8th International Conference on Global Resource Conservation (ICGRC 2017), p. (pp.040001). 19th - 20th July 2017. Malang: UB Hotel.

Skudra, I. \& Ruza, A. (2017) 'Effect of nitrogen and sulphur fertilization on chlorophyll content in winter wheat', Rural Sustainability Research, 37(332), pp.29-37. doi: 10.1515/plua-2017-0004.

USDA [The United States Department of Agriculture]. (2020a). FoodData Central: Lettuce, raw. https://fdc.nal.usda.gov/fdc-app.html\#/food-details/787797/nutrients. [17 ${ }^{\text {th }}$ August 2020].

USDA [The United States Department of Agriculture]. (2020b). 'Food Data Central: Spinach, raw. https://fdc.nal.usda.gov/fdc-app.html\#/food-details/787373/nutrients. [17th August 2020].'

Vermeulen, T. \& Kamstra, A. (2013). 'The need for systems design for robust aquaponic systems in the urban environment. In: Zhu, W. \& Li, Q. (ed).', in ISHS Acta Horticulturae 1004: International Symposium on Soilless Cultivation, China: Shanghai, pp.71-78.

Vimolmangkang, S., Sitthithaworn, W., Vannavanich, D., Keattikunpairoj, S., Chittasupho, C. (2010) 'Productivity and quality of volatile oil extracted from Mentha spicata and M. arvensis var. piperascens grown by a hydroponic system using the deep flow technique.', Journal of Natural Medicines, 64(1), pp.31-35. doi: 10.1007/s11418-009-0361-5.

Warganegara, G. R., Ginting, Y. C. \& Kushendarto, K. (2015) 'Pengaruh konsentrasi nitrogen dan plant catalyst terhadap pertumbuhan dan hasil tanaman selada (Lactuca Sativa L.) secara hidroponik', Jurnal Penelitian Pertanian Terapan, 15(2), pp.100-106. doi: 10.25181/jppt.v15i2.117.

Wen, B., Li, C., Fu, X., Li, D., Li, L., Chen, X., Wu, H., Cui, X., Zhang, X., Shen, H., et al. (2019) 'Effects of nitrate deficiency on nitrate assimilation and chlorophyll synthesis of detached apple leaves', Plant Physiology and Biochemistry, 142, pp.363-371. doi: 10.1016/j.plaphy.2019.07.007. 